\title{
Vibration recycling technologies for mining and mineral processing waste for construction purposes
}

\author{
Alexandr Samukov ${ }^{1}$, Margarita Cherkasova ${ }^{2}$ \\ REC "Mekhanobr-Tekhnika”, Saint Petersburg, Russia \\ ${ }^{2}$ Corresponding author \\ E-mail: ${ }^{1}$ samykov_ad@npk-mt.spb.ru, ${ }^{2}$ cherkasova_mv@npk-mt.spb.ru
}

Received 6 May 2019; accepted 24 May 2019

DOI https://doi.org/10.21595/vp.2019.20778

Check for updates

Copyright (C) 2019 Alexandr Samukov, et al. This is an open access article distributed under the Creative Commons Attribution License, which permits unrestricted use, distribution, and reproduction in any medium, provided the original work is properly cited.

\begin{abstract}
The problem of waste generation and recycling in the production of building crushed stone is considered. A comprehensive approach is proposed, involving developing of new technologies based on the application of vibration effects. The main scientific novelty of the solutions consists in the wide use of vibration effects and equipment to solve the most complex technology problems, in the same time with the substantiation of technological conditions and ingredients compositions. The results allow improving the grade of commercial crushed stone, while reducing the output of crushing screenings, and recycling of the screenings with the production of high-grade graded artificial sand and vibration compacted products based on this sand. A technology is developed for utilizing the dust-like component of the waste for the production of mineral wool. The environmental effects from the proposed technological solutions are evaluated.
\end{abstract}

Keywords: recycling of crushing screenings, vibratory crusher, vibrating screen, artificial graded sand, vibration compacted products, mineral wool.

\section{Introduction}

The construction industry in the Russian Federation produces over 300 million cubic meters of crushed stone annually. At the same time approximately $30 \%$ to $45 \%$ of the rock is discarded as waste, which is stored at industrial sites of crushing and screening plants, occupying vast areas. The following two types of waste are generally formed out of igneous rocks.

1. Quarry fines. This is a product of less than $20 \mathrm{~mm}$, formed during blasting in open pits, along with large material pieces. Quarry fines are currently not used for the manufacture of crushed stone while being suitable in terms of their fineness. Due to the destruction by blasting, quarry fines contain up to $50 \%$ of flaky and needle-shaped grains, are contaminated with moisture-laden clay varieties and represent a material that is hardly fit for processing. Quarry fines are screened before primary crushing; the resulting waste is approximately $10 \%$ of the total rock mass mined.

2. Crushing screenings. This is the overground fraction formed in the destruction of rock in crushing equipment. It is recovered from crushing products by screening to the grain size of $5 \mathrm{~mm}$. It averages $20 \%$ to $35 \%$ of the rock mass extracted.

Recycling of crushed stone production screenings is an important national economic task, which, if solved, will bring substantial profits to the country's economy and will significantly improve the economic performance of mining enterprises by increasing the output of marketable products.

However, the qualified use of screenings is limited by two significant factors. Firstly, the grain-size distribution and high content of flaky grains prevent the full use of screenings in substitution of building sand. And secondly, transportation of screenings causes great technical difficulties due to the high content of dust fractions and is not economically feasible.

The following measures must be ensured in order to effectively address these problems:

- Reducing the output of the screenings fraction in the processing of non-metallic materials; 
- Recycling of mining and processing waste for non-metallic raw materials to obtain materials for the manufacture of concrete products and dry construction mixes and to release the land occupied by the waste.

Vibration technologies have long been successfully used in the production of crushed stone but mainly for the classification of products by size fractions. The research was carried out with the aim to develop processes which allow modifying certain physical and mechanical properties of the waste so it can be used for the manufacture of products with higher cost to ensure the profitability of their transportation to the regions of consumption. For that purpose novel technologies including vibrational impact in separation and disintegration processes were developed, which are described below.

The integrated approach to the technology of recycling, developed by our specialists, envisages the following:

- The use of vibratory crushing equipment, producing vibration and pulse effects on the material processed and causing its destruction along the cleavage planes, ensures the recovery of the maximum amount of cuboid grains while reducing overgrinding.

- The use of a vibrating drying and dedusting facility, creating a vibrofluidized bed of wet material due to vibration effects, enables effective drying and dedusting. This device ensures significant fuel savings as compared to traditional drying in rotary tubular kilns.

- The use of vibrating screens with a reinforced design enables effective multi-fractional classification of materials at high vibration frequencies and lower amplitude of oscillations.

- The use of vibratory crushing equipment for processing the dust fraction of screenings $(0-0.63 \mathrm{~mm})$ with addition of a binder. The resulting product may be used as a sealing additive to improve the rheological properties of fine-grained concrete mixes and reduce binder consumption.

- The use of vibration equipment to produce vibration compacted products from artificial graded sand, as well as to form pellets to be used as the raw material for the manufacture of mineral wool.

The main scientific novelty of the solutions consists in the wide use of vibration effects and equipment to solve the most complex technology problems, in the same time with the substantiation of technological conditions and ingredients compositions. The following processes were developed:

- Reducing output of screenings in the main process;

- Production of the highquality crushed stone from gross fraction of quarry fines and screenings;

- Obtaining of artificial sand from screenings;

- Production of vibration compacted concrete products using artificial sand;

- Production of mineral wool from dust fraction of screenings.

\section{Minimization of the formation of screenings}

The main idea behind the minimization of screening output in crushed stone production is the use of crushing vibratory machines at the final processing stage to produce the vibration and pulse effect on the material processed. This will ensure the minimum recovery of flaky and needle-shaped (uncuboid) grains while reducing overgrinding.

Vibratory cone crushers are distinguished by the fact that the concave is driven by an unbalanced vibration exciter [1] and not by an eccentric mechanism, as in standard machines. When this drive is used, the bed of the material crushed experiences repeated impulse effects of a high crushing force.

A comparison of crushed product characteristics for eccentric and vibratory crushers of the same capacity demonstrates that the latter ensure, in particular, $15 \%$ to $20 \%$ higher recovery of the $5-20 \mathrm{~mm}$ finished class than the standard option, which significantly reduces the circulating material volume and the output of the $0-5 \mathrm{~mm}$ fraction (screenings).

At the same time, the proportion of flaky and needle-shaped grains in the product obtained 
using crushers with eccentric drives is near $35 \%$, while the value for vibratory crushers is less than $15 \%[2,3]$.

When the task is to obtain fine crushed stone with the content of flaky and needle-shaped grains below $15 \%$ in a process flow with standard crushers, an additional stage of the so-called granulation must be introduced, for which centrifugal impact crushers are usually used. This allows reducing the output of flaky and needle-shaped grains, but also cuts the recovery of crushed stone down to $45 \%$, while the use of vibratory crushers as the third stage ensures the crushed stone output of $58 \%$ (see Fig. 1). This is due to the larger circulation volume and the corresponding overgrinding of the material in the impact crusher, which increases the recovery of the $0-5 \mathrm{~mm}$ fraction.

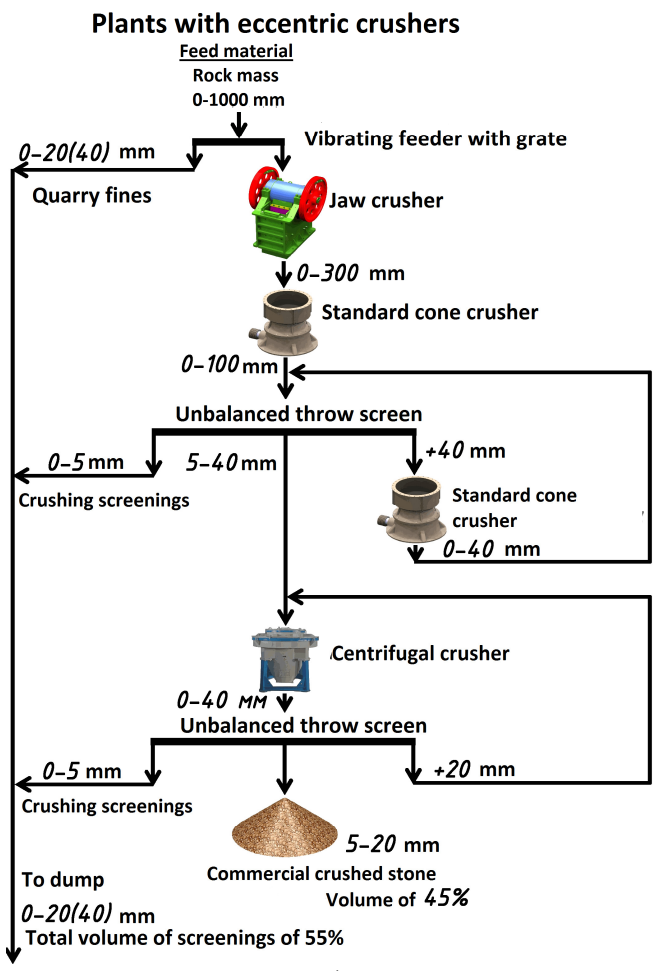

a)

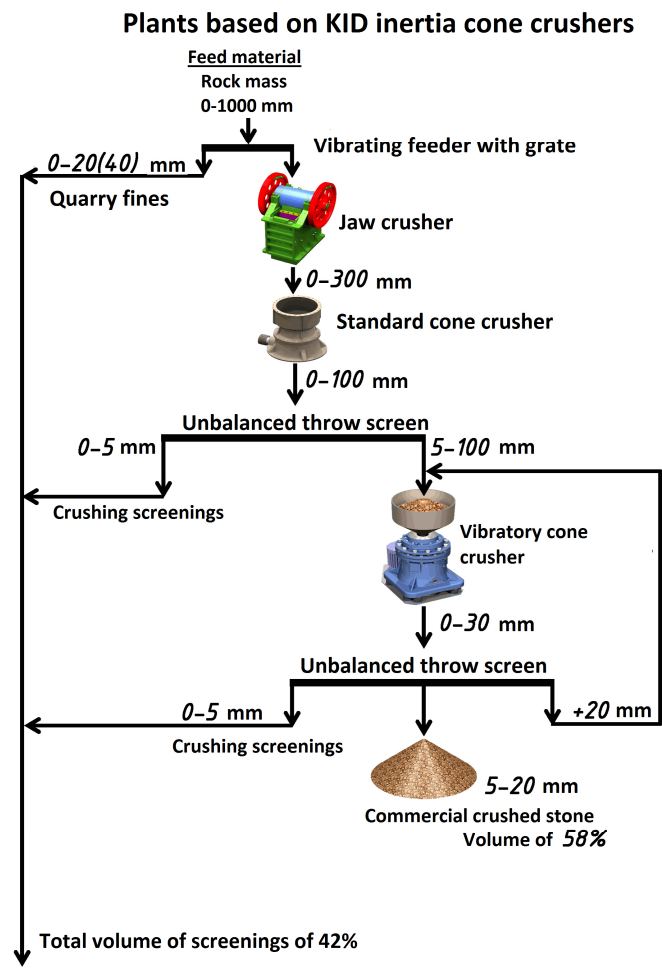

b)

Fig. 1. Flow chart for crushed stone fraction 5-20 $\mathrm{mm}$ production with the content of needle-shaped and flaky grains of less than $15 \%$

\section{Production artificial sand}

The main idea behind the technology for artificial sand producing developed (see Fig. 2) can be described as follows [4]:

- The 5-40 fraction, recovered from a mixture of screenings and quarry fines, undergoes grain shape and size distribution modification in a vibratory crusher. After the crushed product is screened, this enables isolating the commercial crushed stone fraction of 5-20 $\mathrm{mm}$ with high grain cubicity;

- Undersize fractions of the material recovered using vibrating screens before and after crushing in a vibratory crusher are combined and sent for vibrating drying and dedusting in a fluidized bed;

- The dried material passes the second stage of grain shape and size distribution modification in a vibratory crusher; 
- The crushed product is graded in order to separate the modified screenings into the narrow size classes of $2.5-5.0 ; 1.25-2.5 ; 0.63-1.25$ and $0.16-0.63 \mathrm{~mm}$. The high-grade artificial sands obtained may be used as aggregates for fine-grained concrete in the manufacture of vibration compacted products. The grade of the fractions isolated is improved using new, more intense types of vibration effects, produced in reinforced unbalanced throw screens, enabling multi-fractional classification of materials at higher vibration frequencies and lower vibration amplitudes [5]. The dust fraction of $0-0.16 \mathrm{~mm}$, selected by aspiration in the screening process, may be used to produce mineral wool.

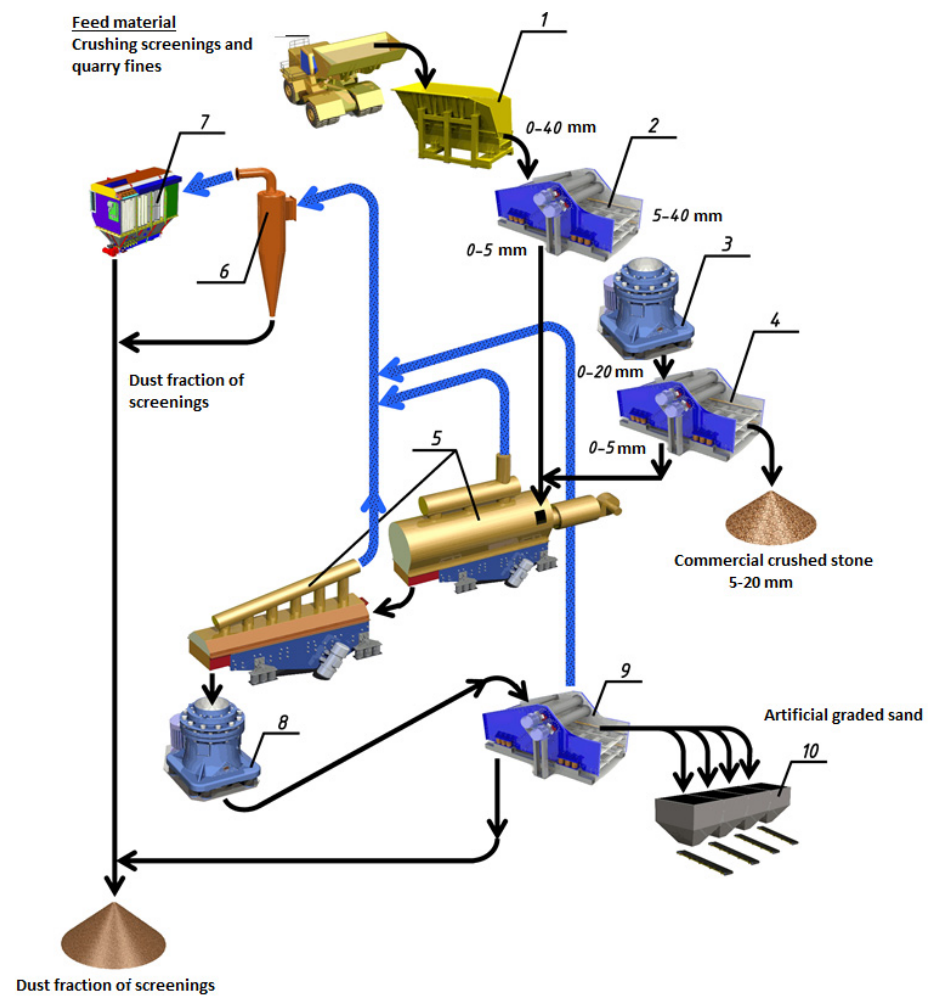

Fig. 2. Schematic diagram for recycling of screenings and quarry fines to produce crushed stone and artificial sand. 1 - feed hopper; 2, 9 - vibrating screens with high-frequency vibrations;

3,8 - KID vibratory inertia cone crusher; 4 - vibrating screen; 5 - vibratory drier with fluidized bed; 6 - cyclone; 7 - bag filter; 10 - artificial sand dispenser

\section{Production technology for vibration compacted concrete products}

Dust-free screening fractions, used as aggregates for the production of vibration compacted concrete products, contribute to reducing the void factor. Processing of fine screenings fractions (0-0.16 and $0.16-0.63 \mathrm{~mm})$ in vibratory crushing equipment with addition of a binder enables their use as sealing additives, which reduces the binder consumption and improves the rheological properties of fine-grained concrete mixes. This advanced method for processing mineral raw materials has been used in the developed technology for the manufacture of vibration compacted concrete products from high-grade artificial sands (see Fig. 3). This technology envisages mixing the components of the fine-grained concrete mix in the desired proportions, including artificial sands and a mixture of cement and fine screenings that was previously mechanically activated in a vibratory crusher. The concrete mix is then fed into a vibrating compactor for the automatic formation and compaction of concrete products. Maturing and hardening of the finished products are carried out in a closed warehouse. 


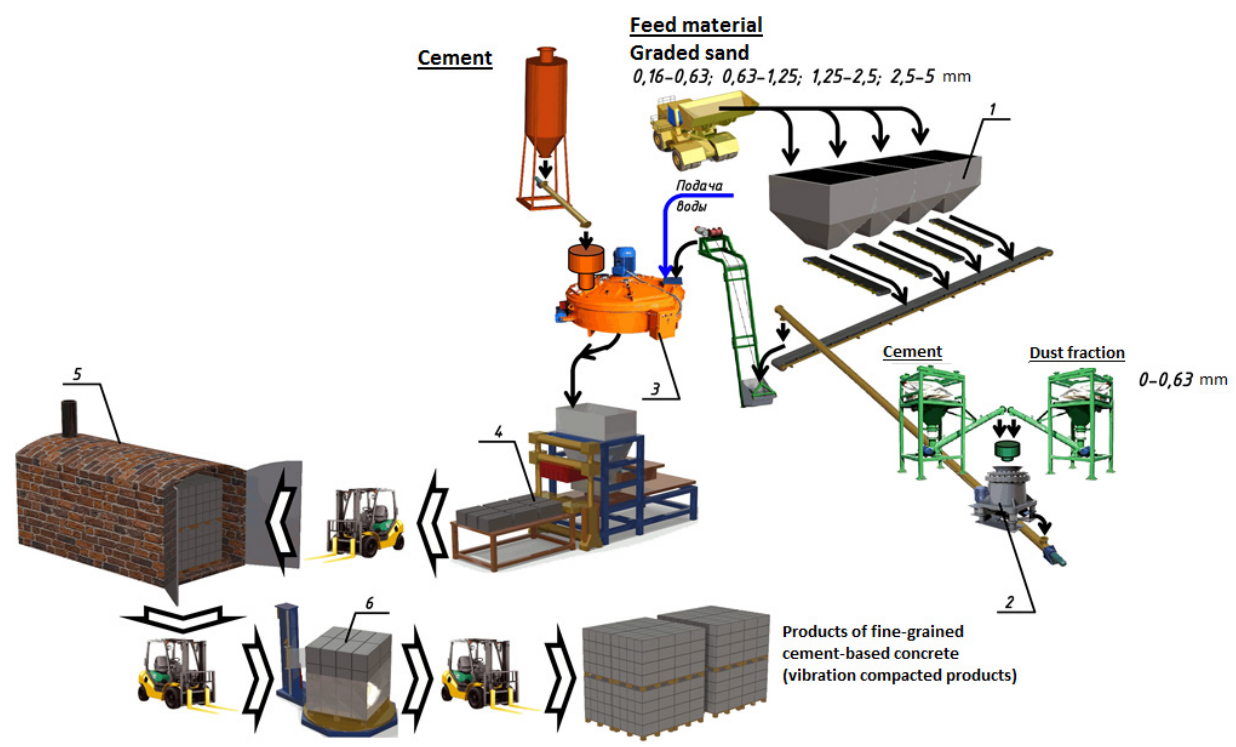

Fig. 3. Schematic diagram for the production of vibration compacted concrete products:

1 - feed hopper with dispenser; 2 - KID vibratory inertia cone crusher; 3 - mixer;

4 - vibrating compactor; 5 - steam-curing chamber; 6 - automated packing machine

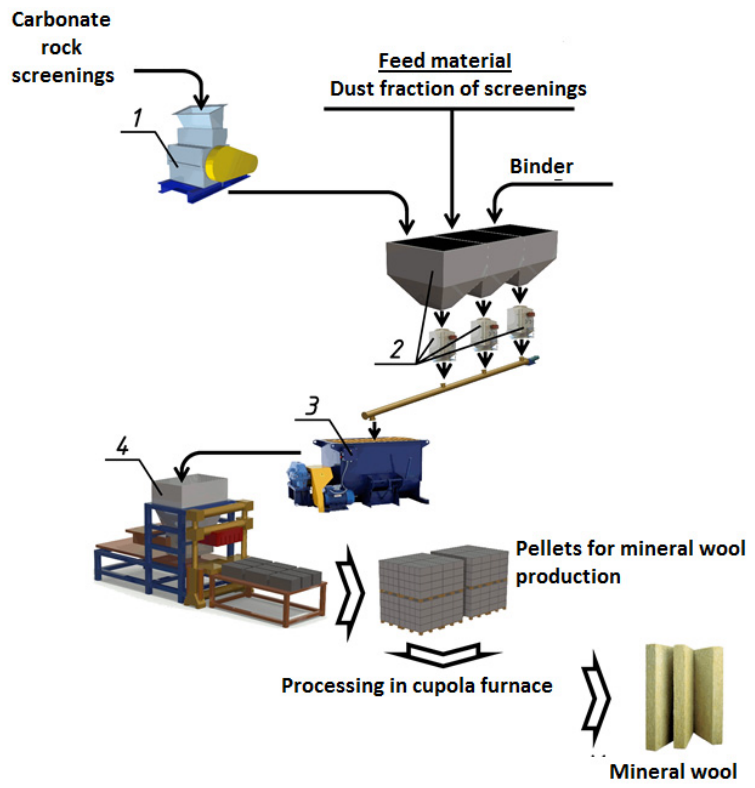

Fig. 4. Schematic diagram of recycling dust fractions of screenings with the production of mineral wool:

1 - rotary disintegrator; 2 -dispensing hoppers; 3 - mixer; 4 - vibrating compactor

\section{Mineral wool production technology}

The problem of recycling the $0-0.16 \mathrm{~mm}$ dust fraction recovered by aspiration, the amount of which sometimes reaches $10 \%$ of the total waste, is extremely urgent. One of the promising options proposed for the processing of the dust fraction of granite rock screenings consists in its use as a raw material for the production of mineral wool.

The respective research rendered the ratio range for the charge components that enables reaching the melt viscosity not exceeding $10 \mathrm{~Pa} \cdot \mathrm{s}$ at the temperature of $1450{ }^{\circ} \mathrm{C}$ and producing 
high-quality mineral wool. The working range includes compositions with the granite dust content of $65 \%$ to $75 \%$. Both cement and bentonite may be used as the binder [6].

The process flow developed (see Fig. 4) envisages charge preparation from the dust fraction of granite screenings and screenings of carbonate rocks, as well as a binder component (not exceeding $5 \%$ ). Vibration compaction is used to form pellets from the resulting mixture. The use of vibration equipment allows forming pellets of high density and strength while reducing water and binder consumption. Steaming is used for hardening vibration compacted products; in this case, the curing period is reduced from 28 days to 7 hours. After the hardening, the pellets shall be suitable for smelting in a cupola furnace with the production of mineral wool using the standard technology.

The method proposed enables almost complete utilization of the dust fraction of screenings, which will reduce the mass of the dusting material annually exported to dumps by $7 \%$ to $30 \%$, with reduced associated negative environmental impact.

\section{Conclusions}

In order to understand the environmental performance of the technologies proposed, an integrated assessment was carried out by means of environmental impact modeling for various dusty waste management scenarios. The assessment showed that the environmental damage prevented will average RUB 1,300 per ton of recycled waste. If the technology is widely introduced across Russia, the dust fraction processing alone will allow achieving the following: annual reduction of dust emissions by 220 thousand tons; reduction of the area occupied by dumps by tens of hectares; total reduction of the environmental damage by RUB 5 billion a year [7].

The environmental effect of preventing the dumping of building crushed stone production waste and the dust fraction of screenings in particular is quite high. Integrated recycling of crushed stone production wastes not only offers great environmental value, but may also significantly contribute to the competitiveness of a production enterprise if implemented using efficient vibration technologies.

\section{Acknowledgements}

The study was carried out under the grant issued by the Russian Science Foundation (Project No. 17-79-30056).

\section{References}

[1] Arsentyev V. A., Vaisberg L. A., Zarogatsky L. P., Shuloyakov A. D. The Production of Cuboid Crushed Stone and Building Sand Using Vibrating Crushers. St. Petersburg, 2004, p. 112.

[2] Vaisberg L. A., Shuloyakov A. D., Orlov S. L., Spiridonov P. A., Dalatkazin A. A. New technologies for the production of fine high-grade cuboid crushed stone. Gornaya Promyshlennost (Mining Industry), Vol. 3, Issue 91, 2010, p. 10-13.

[3] Vaisberg L. A., Kameneva E. E., Aminov V. N. Evaluation of technological capabilities of crushed stone grade management in disintegration of building rocks. Stroitelnye Materialy (Building Materials), Vol. 11, 2013, p. 30-34.

[4] Arsentyev V. A., Vaisberg L. A., Shuloyakov A. D., Romashev A. O. Waste disposal technologies for the production of inert non-metallic materials. Obogashchenie Rud (Mineral Processing Journal), Vol. 5, 2012, p. 51-54.

[5] Korovnikov A. N., Trofimov V. A. A new generation of screens for the building materials industry. Stroitelnye Materialy (Building Materials), Vol. 7, 2008, p. 14-17.

[6] Bortnikov A. V., Samukov A. D., Spiridonov P. A., Shuloyakov A. D. Development of the charge preparation technology for the production of mineral wool based on the use of mineral processing waste. Obogashchenie Rud (Mineral Processing Journal), Vol. 3, 2015, p. 51-55.

[7] Mikhailova N. V. Evaluation of the environmental efficiency of using the dust fraction of granite screenings. Obogashchenie Rud (Mineral Processing Journal), Vol. 6, 2016, p. 57-61. 